\title{
Pentosan Polysulfate Sodium
}

National Cancer Institute

\section{Source}

National Cancer Institute. Pentosan Polysulfate Sodium. NCI Thesaurus. Code C946.

The sodium salt of a semisynthetic heparin-like glucosaminoglycan. Although its mechanism of action is unknown, pentosan polysulfate may act as a buffer to control cell permeability by preventing irritating solutes from reaching cells coated with it.

Administered orally, excreted pentosan polysulfate adheres to the urinary bladder wall, preventing irritants from entering bladder cells and the development or progression of interstitial cystitis (IC), a complication of some chemotherapies. This agent also exhibits anticoagulant and fibrinolytic properties. 